Article

\title{
Antimicrobial Resistance in Bacterial Pathogens and Detection of Carbapenemases in Klebsiella pneumoniae Isolates from Hospital Wastewater
}

\author{
Hercules Sakkas * $\mathbb{D}$, Petros Bozidis $\mathbb{D}^{\mathrm{D}}$, Afrodite Ilia, George Mpekoulis and \\ Chrissanthy Papadopoulou \\ Microbiology Department, Faculty of Medicine, School of Health Sciences, University of Ioannina, \\ 45110 Ioannina, Greece \\ * Correspondence: isakkas@uoi.gr; Tel.: +30-265-100-7769
}

Received: 21 May 2019; Accepted: 26 June 2019; Published: 27 June 2019

\begin{abstract}
During a six-month period (October 2017-March 2018), the prevalence and susceptibility of important pathogenic bacteria isolated from 12 hospital raw sewage samples in North Western Greece was investigated. The samples were analyzed for methicillin-resistant Staphylococcus aureus (MRSA), vancomycin-resistant enterococci (VRE), extended-spectrum beta-lactamase (ESBL) producing Escherichia coli, carbapenemase-producing Klebsiella pneumoniae (CKP), and multidrug-resistant Pseudomonas aeruginosa. Antimicrobial susceptibility testing was performed using the agar diffusion method according to the recommendations of the Clinical and Laboratory Standards Institute. The diversity of carbapenemases harboring K. pneumoniae was examined by two phenotyping screening methods (modified Hodge test and combined disk test), a new immunochromatographic rapid assay (RESIST-4 O.K.N.V.) and a polymerase chain reaction (PCR). The results demonstrated the prevalence of MRSA, vancomycin-resistant Staphylococcus aureus (VRSA), VRE, and CKP in the examined hospital raw sewage samples. In addition, the aforementioned methods which are currently used in clinical laboratories for the rapid identification and detection of resistant bacteria and genes, performed sufficiently to provide reliable results in terms of accuracy and efficiency.
\end{abstract}

Keywords: Multidrug-resistance; wastewater; carbapenemases; MRSA; VRSA; VRE; ESBL; CKP; immunochromatographic test; PCR

\section{Introduction}

The use of antimicrobials for the treatment of human infections started in the 1900s with Salvarsan (1909) for treatment of syphilis and the discovery of Prontosil (1935), a sulfonamide. Prontosil is the oldest antimicrobial on market and the first to be linked with development of resistance (sulfa drug resistance) due to its extensive use since, Prontosil was the first and only effective antibiotic available in the years before penicillin (1942) [1]. Like sulfonamides, penicillin was extensively used, resulting in the development of resistant bacteria. Between the 1950s and 1970s novel antibiotic classes were discovered and used for the treatment or prevention of human and animal infections. However, the lessons learned from the extensive use of sulfa-drugs and penicillin were not enough to stop the emergence of resistance to new antibiotic classes. As the mortality rates due to multi-drug resistant bacterial infections increase there are concerns that the "golden era of antibiotics" may be followed by the "era with no antibiotics". The anti-microbial resistance (AMR) phenomenon is currently one of the most important public health issues, and antibiotic resistance genes (ARGs) are considered the emerging pollutant of the environment [2]. 
ESKAPE bacteria (Enterococcus faecium, Staphylococcus aureus, Klebsiella pneumoniae, Acinetobacter baumannii, Pseudomonas aeruginosa, Enterobacter species) are globally the leading cause of severe healthcare-acquired infections in hospital settings with limited or no antimicrobial treatment options due to AMR [3]. Infected and colonized hospital patients can disseminate ESKAPE bacteria or other drug-resistant bacteria through their excreta usually together with active antimicrobial compounds; thus, hospital effluents constitute the ideal pool for the exchange of resistance genes between clinical and environmental bacteria [4,5]. Studies on the efficiency of wastewater treatment plants show that neither primary or secondary treatment can eliminate efficiently multidrug-resistant bacteria from sewage. Resistant bacteria and genes, surviving the hospital sewage treatment processes can spread and persist in the environment posing a steady reservoir of AMR and a constant health risk for humans and animals [6,7].

Enterococcus spp. exhibit intrinsic and acquired resistance to various antibiotics, particularly to vancomycin [8]. Vancomycin-resistant enterococci (VRE) capable of spreading resistance genes (van $A$, vanB) to vancomycin-susceptible strains have emerged worldwide, with several EU countries reporting VRE rates $>10 \%$ [9] mainly by E. faecium [10]. Methicillin-resistant S. aureus (MRSA) is reported to have a declining trend in recent years (from 19.6\% in 2014 to $16.9 \%$ in 2017) in a third of EU countries, but large differences ranging from $1 \%$ (Norway) to $44.4 \%$ (Romania) are observed among the reporting countries [11]. A. baumannii and P. aeruginosa are increasingly implicated in hospital-acquired infections exhibiting resistance to most of the available antimicrobial treatments [12]. Enterobacter spp. and E. coli have the potential to develop mechanisms of antibiotic resistance, including ESBLs and carbapenemases $[13,14]$. Over the past years, K. pneumoniae is considered a major opportunistic pathogen, colonizing the skin, gastrointestinal and respiratory tract, causing a range of severe nosocomial and community-acquired infections like pneumonia and meningitis, as well as wound, urinary tract and bloodstream infections, particularly in neonates, elderly and immunocompromised individuals $[15,16]$. In patients with Klebsiella spp infections, bacteria can be transmitted usually via direct personal contact, medical equipment and contaminated environments [17]. In hospital settings K. pneumoniae has been considered one of the most frequent agents of infectious diseases and significant threat to public health because of the high rates of antimicrobial resistance. There are limited data on environmental Klebsiella spp isolates, but the existing studies show similarities in phenotypic and genetic characteristics [15,17]. The increasing prevalence of carbapenems-resistant K. pneumoniae is a public health concern of major importance in Europe, particularly in Greece reporting the highest percentages (60.5\%) of carbapenem-resistant K. pneumoniae isolates [18]. The most important beta lactamases conferring resistance to carbapenems that have already been detected in Enterobacteriaceae are K. pneumoniae carbapenemases (KPC, Ambler class A), metallo- $\beta$-lactamases (MBL, Ambler class B) and members of class D $\beta$-lactamases such as OXA-48 [19].

The aim of the present study was to assess the occurrence of clinically important multidrug-resistant bacteria, including MRSA, vancomycin-resistant S. aureus (VRSA), VRE, ESBL-producing bacteria, carbapenemase-producing K. pneumoniae (CKP) and P. aeruginosa, in raw hospital sewage in order to determine the antimicrobial resistance profile of the isolates, and to define the diversity of carbapenemases harboring $K$. pneumoniae isolates, using a new immunochromatographic rapid assay, two phenotyping screening methods and a 'gold standard' molecular method.

\section{Materials and Methods}

\subsection{Sample Collection and Bacterial Isolation}

During a six-month period (October 2017-March 2018), 12 raw untreated sewage samples from a tertiary hospital (Ioannina, Greece) were collected. Samples of $0.5 \mathrm{~L}$ each were placed into sterile bottles, transported to the laboratory on ice packs in portable insulated containers and processed within $24 \mathrm{~h}$. Samples were concentrated using the filtration technique onto $0.45-\mu \mathrm{m}$ pore size filter membranes (Merck, Darmstadt, Germany). Membranes were placed onto the surface of differential 
selective agars; MacConkey agar supplemented with $1 \mu \mathrm{g} / \mathrm{ml}$ imipenem (Oxoid Ltd., Basingstoke, UK), Chapman and Bile Aesculin media, (Oxoid Ltd., Basingstoke, UK). Plates were incubated for $24 \mathrm{~h}$ at $37^{\circ} \mathrm{C}$ in air. Selected colonies were transferred to selective chromogenic media CHROMagar MRSA, CHROMagar VRE, CHROMagar ESBL, CHROMagar KPC, CHROMagar Pseudomonas (CHROMagar, Paris, France) $\left(24 \mathrm{~h}, 37^{\circ} \mathrm{C}\right)$. The identification of isolated species was determined using the API Staph, API 20 STREP and API 20E identification systems (bioMerieux SA, Marcy-l'Etoile, France).

\subsection{Antimicrobial Susceptibility Testing}

Antimicrobial susceptibility testing was performed by applying the agar diffusion method according to the Clinical and Laboratory Standards Institute (CLSI) recommendations [20], including the following antibiotics: Penicillin G (10 U), ampicillin (10 $\mu \mathrm{g})$, amoxicillin/clavulanate $(20 / 10 \mu \mathrm{g})$, piperacillin/tazobactam $(100 / 10 \mu \mathrm{g})$, ticarcillin/clavulanate $(75 / 10 \mu \mathrm{g})$, vancomycin $(30 \mu \mathrm{g})$, teicoplanin $(30 \mu \mathrm{g})$, erythromycin $(15 \mu \mathrm{g})$, clindamycin $(2 \mu \mathrm{g})$, amikacin $(30 \mu \mathrm{g})$, gentamicin $(10 \mu \mathrm{g})$, tobramycin $(10 \mu \mathrm{g})$, cefoxitin $(30 \mu \mathrm{g})$, ceftriaxone $(30 \mu \mathrm{g})$, ceftazidime $(30 \mu \mathrm{g})$, cefepime $(30 \mu \mathrm{g})$, ciprofloxacin $(5 \mu \mathrm{g})$, imipenem $(10 \mu \mathrm{g})$, meropenem $(10 \mu \mathrm{g})$, quinupristin/dalfopristin $(15 \mu \mathrm{g})$, linezolid $(30 \mu \mathrm{g})$, colistin $(10 \mu \mathrm{g})$, aztreonam $(30 \mu \mathrm{g})$, trimethoprim/sulfamethoxazole $(1.25 / 23.75 \mu \mathrm{g})$, tetracycline $(30 \mu \mathrm{g})$ (Oxoid Ltd., Basingstoke, UK). S. aureus strains were tested against penicillin G, erythromycin, clindamycin, gentamicin, cefoxitin, ciprofloxacin, quinupristin/dalfopristin, whereas Enterococcus species were examined against penicillin G, ampicillin, vancomycin, teicoplanin, erythromycin, ciprofloxacin, quinupristin/dalfopristin, linezolid and tetracycline. Antimicrobial susceptibility testing for Enterobacteriaceae included amoxicillin/clavulanate, amikacin, gentamicin, cefoxitin, ceftriaxone, ceftazidime, cefepime, ciprofloxacin, aztreonam, trimethoprim/sulfamethoxazole, tetracycline, ampicillin (for E. coli) and tobramycin (for Klebsiella spp). P. aeruginosa isolates were tested against piperacillin/tazobactam, ticarcillin/clavulanate, amikacin, gentamicin, tobramycin, ceftazidime, cefepime, ciprofloxacin, imipenem, meropenem and aztreonam. In addition, the minimum inhibitory concentration (MIC) test was performed to determine the resistance of MRSA to vancomycin and teicoplanin, the resistance of K. pneumoniae to imipenem, meropenem, and tigecycline, as well as the resistance of P. aeruginosa to colistin (Liofilchem, Roseto degli Abruzzi (TE), Italy) following the CLSI breakpoints [20].

\subsection{Phenotyping Screening and Carbapenemases Detection}

Imipenem and meropenem resistant Klebsiella isolates were tested for carbapenemases production using: (1) the modified Hodge test (MHT), (2) the meropenem combined disk test (CDT), (3) the RESIST-4 O.K.N.V immunochromatographic test (IT) and (4) a multiplex PCR assay.

MHT is a relatively simple screening test for routine detection of carbapenemases and it is based on the inactivation of a carbapenem by carbapenemase-producing strains that enable a carbapenem-susceptible indicator strain (E. coli ATCC 25922 strain), to extend growth towards a carbapenem-containing disc along the streak of inoculum of the test strain. A positive test result gives a clover leaf-like indentation. The MHT was performed according to the following procedure: a 1:10 dilution of 0.5 McFarland E. coli ATCC 25922 inoculum was placed onto Mueller Hinton agar (MHA) (Oxoid Ltd., Basingstoke, UK) surface with a disk of meropenem $(10 \mu \mathrm{g})$ in the center of the plate. K. pneumoniae ATCC BAA- 1705 was used as a positive control. The Klebsiella isolates to be tested were inoculated, each one in a straight line from the edge of the meropenem disk to the edge of the plate; they were incubated overnight in ambient air $\left(37^{\circ} \mathrm{C}, 24 \mathrm{~h}\right)$ and an interpretation of the results followed. The result was considered positive (indicating carbapenemase production by the test isolate) when a clover leaf-type indentation within the zone of inhibition of the meropenem susceptibility disk [20].

CDT is routinely used for differentiating carbapenemase-producing enterobacteria, and in this study was performed as previously described by Pournaras et al. [21]; MHA was inoculated with $0.5 \mathrm{McFarland}$ dilution of each carbapenem-resistant strain, and disks of meropenem $(10 \mu \mathrm{g})$ alone, meropenem with phenylboronic acid (PBA), meropenem with EDTA and meropenem with both PBA 
and EDTA (Liofilchem, Roseto degli Abruzzi (TE), Italy) were placed onto the surface of plates [22]. Three CKP from our collection (KPC, VIM and NDM-producing K. pneumoniae were used as positive controls). After incubation $\left(37^{\circ} \mathrm{C}, 24 \mathrm{~h}\right)$, a 5-mm difference between the inhibition zones of meropenem disk with the inhibitors PBA, EDTA and PBA/EDTA and meropenem alone, was considered as a positive result for detection of KPC, MBL or KPC/MBL carbapenemases respectively [21].

RESIST-4 O.K.N.V (CORIS, BioConcept, Gembloux, Belgium) can detect the four most prevalent carbapenemases (OXA-48-like, KPC, NDM, VIM). Detection of CKP isolates by RESIST-4 O.K.N.V was performed on pure cultures grown on MacConkey agar for $24 \mathrm{~h}$, according to the manufacturer's recommendations. This recently developed rapid test [23-28] is based on membrane technology with colloidal gold nanoparticles. Each test consists of two lateral-flow cassettes with a nitrocellulose membrane which is sensitized with monoclonal antibodies against KPC, OXA-48, NDM and VIM carbapenemases. After the preparation procedure and a 15-minute reaction, the appearance of a reddish-purple band at test line positions confirms a positive result. Quality control was performed by using the three aforementioned positive CDT clinical isolates and an OXA-48-like-producing clinical isolate from our collection.

A previously published multiplex PCR with primers targeting the $b l a_{\mathrm{VIM}}, b l a_{\mathrm{OXA}-48}, b l a_{\mathrm{NDM}}$, and $b l a_{\mathrm{KPC}}$ genes [29] was used. The final volume of $50 \mu \mathrm{L}$ PCR reaction was containing $2-3 \mu \mathrm{L}$ of total DNA, $1 \times$ HotStarTaq PCR buffer (Tris pH 8.7, KCl, $\left(\mathrm{NH}_{4}\right)_{2} \mathrm{SO}_{4}, 1.5 \mathrm{mM} \mathrm{MgCl}_{2}, 200 \mu \mathrm{M}$ dNTP, 40pmol of each of the VIM-F, VIM-R, OXA-F, OXA-R, NDM-F, NDM-R, KPC-F and KPC-R specific primers [29] and $1 \mathrm{U}$ of HotStarTaq DNA polymerase (Qiagen, Germantown, USA). The amplification program involved an initial denaturation at $94{ }^{\circ} \mathrm{C}$ for $10 \mathrm{~min}$ followed by 36 cycles of $94{ }^{\circ} \mathrm{C}$ for $30 \mathrm{~s}, 52^{\circ} \mathrm{C}$ for $40 \mathrm{~s}$ at $72{ }^{\circ} \mathrm{C}$ for $50 \mathrm{~s}$ with a final extension at $72{ }^{\circ} \mathrm{C}$ for $50 \mathrm{~s}$. The same program was used for the identification of Enterococcal species E. faecalis and E. faecium using the specific primers DD13, DD3-2 and FAC1-1, FAC2-1 accordingly [30]. All PCR products were analyzed by electrophoresis on a $2 \%$ agarose gel in $1 \times$ TBE buffer stained with ethidium bromide $(10 \mu \mathrm{M})$ and visualized under UV light.

\section{Results}

In total, 70 resistant isolates (13 Gram positive and 57 Gram negative) were identified; S. aureus $(n=6)$, Enterococcus spp $(n=7)$, E. coli $(n=24)$, K. pneumoniae $(n=24)$ and P. aeruginosa $(n=9)$. All S. aureus isolates were resistant to both penicillin and oxacillin (tested by cefoxitin disk test). Among the six MRSA strains one was also resistant to vancomycin (16.7\%), while the overall prevalence of VRE was 57.1\%. In addition, nine (100\%), 23 (95.8\%) and 20 (83.3\%) of all P. aeruginosa, K. pneumoniae and $E$. coli isolates respectively, were identified as multidrug-resistant (resistance to three or more antibiotics classes tested), whereas five isolates out of 57 Gram negative bacteria (E. coli, $n=4$ and K. pneumoniae, $n=1)$ were not classified as multidrug-resistant $(8.8 \%)$. Colistin revealed the lowest resistance in P. aeruginosa isolates $(n=2,22.2 \%)$ and 19 out of $24 \mathrm{~K}$. pneumoniae isolates were resistant to carbapenems $(79.2 \%)$, while one out of the 19 carbapenem- resistant isolates was resistant to tigecycline (5.3\%) (Table 1, Tables S1-S5). 
Table 1. Antibiotic resistance (\%) profile of tested bacteria.

\begin{tabular}{|c|c|c|c|c|c|}
\hline Bacteria/Antibiotics * & $\begin{array}{c}\text { S.aureus } \\
(n=6)\end{array}$ & $\begin{array}{c}\text { Enterococcus } \\
\operatorname{spp}(n=7)\end{array}$ & $\begin{array}{c}\text { E. coli } \\
(n=24)\end{array}$ & $\begin{array}{c}\text { K. pneumoniae } \\
(n=24)\end{array}$ & $\begin{array}{c}P . \text { aeruginosa } \\
(n=9)\end{array}$ \\
\hline PEN & $100 \%$ & $57.1 \%$ & & & \\
\hline AMP & & $85.7 \%$ & $100 \%$ & & \\
\hline AMC & & & $79.2 \%$ & $75 \%$ & \\
\hline PTZ & & & & & $55.5 \%$ \\
\hline TCC & & & & & $77.7 \%$ \\
\hline VAN & $16.7 \%$ & $57.1 \%$ & & & \\
\hline TEC & $16.7 \%$ & $57.1 \%$ & & & \\
\hline ERY & $100 \%$ & $71.4 \%$ & & & \\
\hline $\mathrm{CC}$ & $100 \%$ & & & & \\
\hline AMK & & & $25 \%$ & $62.5 \%$ & $88.8 \%$ \\
\hline GEN & $66.6 \%$ & & $29.2 \%$ & $45.8 \%$ & $88.8 \%$ \\
\hline TOB & & & & $100 \%$ & $100 \%$ \\
\hline FOX & $100 \%$ & & $66.6 \%$ & $83.3 \%$ & \\
\hline CRO & & & $100 \%$ & $100 \%$ & \\
\hline CAZ & & & $70.8 \%$ & $95.8 \%$ & $33.3 \%$ \\
\hline FEP & & & $54.2 \%$ & $83.3 \%$ & $66.6 \%$ \\
\hline CIP & $100 \%$ & $71.4 \%$ & $79.2 \%$ & $87.5 \%$ & $88.8 \%$ \\
\hline IPM & & & & $79.2 \%$ & $88.8 \%$ \\
\hline MEM & & & & $79.2 \%$ & $100 \%$ \\
\hline ATM & & & $45.8 \%$ & $58.3 \%$ & $55.5 \%$ \\
\hline QDA & $33.3 \%$ & $100 \%$ & & & \\
\hline LZD & & $85.7 \%$ & & & \\
\hline SXT & & & $66.6 \%$ & $95.8 \%$ & \\
\hline $\mathrm{CT}$ & & & & & $22.2 \%$ \\
\hline TET & & $71.4 \%$ & $45.8 \%$ & $58.3 \%$ & \\
\hline TGC & & & & $5.3 \%$ & \\
\hline
\end{tabular}

* PEN, penicillin G; AMP, ampicillin; AMC, amoxicillin/clavulanate; PTZ, piperacillin/tazobactam; TCC, ticarcillin/clavulanate; VAN, vancomycin; TEC, teicoplanin; ERY, erythromycin; CC, clindamycin; AMK, amikacin; GEN, gentamicin; TOB, tobramycin; FOX, cefoxitin; CRO, ceftriaxone; CAZ, ceftazidime; FEP, cefepime; CIP, ciprofloxacin; IPM, imipenem; MEM, meropenem; ATM, aztreonam; QDA, quinupristin/dalfopristin; LZD, linezolid; SXT, trimethoprim/sulfamethoxazole; CT, colistin; TET, tetracycline; TGC, tigecycline.

The molecular screening of carbanemase genes was based on a previously published multiplex PCR technique [29]. Nineteen K. pneumoniae isolates positive for class A (bla $\left.a_{\mathrm{KPC}}\right)$ and class B $\left(b l a_{\mathrm{NDM}}\right.$ and $b l a_{\mathrm{VIM}}$ ) genes by immunochromatographic test (IT) were screened against $b l a_{\mathrm{KPC}}, b l a_{\mathrm{NDM}}, b l a_{\mathrm{OXA}-48}$ and $b l a_{\mathrm{VIM}}$ genes using the appropriate primers. The multiplex PCR reaction produced amplicons with the expected length of 798bp, 621bp, 438bp and 390bp respectively (Figure 1). RESIST-4 O.K.N.V and PCR assays identified the same carbapenemase gene in 17 out of the $19(89.5 \%)$ isolates. The immunoassay detected the $b l a_{\mathrm{KPC}}$ or $b l a_{\mathrm{VIM}}$ genes in two samples $(10.5 \%)$, which were positive for both genes by PCR. None of these isolates was positive for bla OXA-48 carbapenemase gene by both methods.

Regarding the phenotypic screening tests, MHT revealed the production of carbapenemases in 15 out of 19 K. pneumoniae isolates $(78.9 \%)$, whereas the CDT identified all the carbapenemase-producing K. pneumoniae isolates. However, in three out of 19 isolates (18.7\%), CDT was considered positive for detection of both KPC and MBL carbapenemases, while only MBL enzymes were detected by PCR. The results from PCR, MHT, CDT and IT tests are presented in Table 2. 


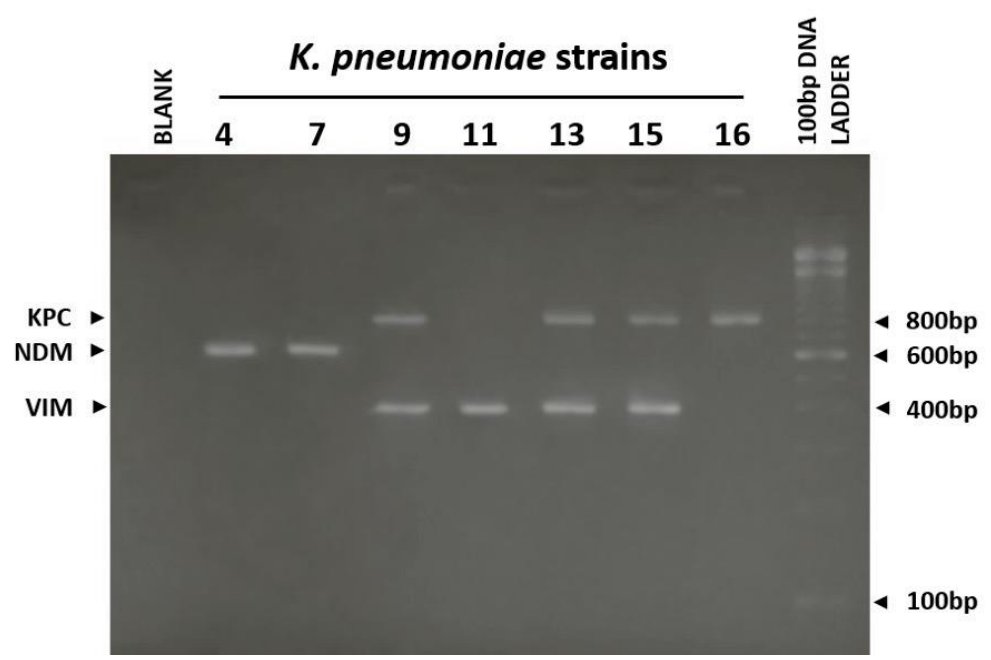

Figure 1. Agarose gel electrophoresis $(2 \% w / v)$ used for the separation of PCR products produced by a multiplex PCR reaction against $b l a_{\mathrm{KPC}}, b l a_{\mathrm{NDM}}, b l a_{\mathrm{OXA}-48}$ and $b l a_{\mathrm{VIM}}$ genes. Blank corresponds to a negative control (without DNA). Bands correspond to PCR products from PCR screening of K.pneumoniae isolates 4,7,9,11,13,15 and isolate 16. The size of each amplicon is indicated on the left. The ladder used is the $100 \mathrm{bp}$ DNA ladder (InvitrogenTM, ThermoFisher Scientific).

A second PCR reaction was used for the identification of the isolated enterococci strains. The primers could amplify specific ddl genes producing amplicons of $475 \mathrm{bp}$ or $1091 \mathrm{bp}$ length for E. faecalis or E. faecium correspondingly. All seven Enterococcus spp isolates were identified as E. faecalis.

Table 2. Phenotyping screening and carbapenemases detection in K.pneumoniae strains by immunochromatographic rapid assay and PCR.

\begin{tabular}{ccccc}
\hline K. pneumoniae & MHT & $\begin{array}{c}\text { CDT ( } \beta \text {-lactamase } \\
\text { detected })\end{array}$ & IT & PCR \\
\hline KP1 & + & KPC/MBL & VIM & VIM \\
KP2 & + & KPC & KPC & KPC \\
KP3 & + & KPC & KPC & KPC \\
KP4 & - & MBL & NDM & NDM \\
KP5 & + & KPC/MBL & KPC+NDM & KPC+NDM \\
KP6 & - & KPC/MBL & KPC+NDM & KPC+NDM \\
KP7 & - & MBL & NDM & NDM \\
KP8 & + & KPC/MBL & KPC+VIM & KPC+VIM \\
KP9 & + & KPC/MBL & KPC+VIM & KPC+VIM \\
KP10 & + & KPC & KPC & KPC \\
KP11 & + & KPC/MBL & VIM & VIM \\
KP12 & + & MBL & VIM & VIM \\
KP13 & + & KPC/MBL & VIM & KPC+VIM \\
KP14 & + & KPC/MBL & KPC+VIM & KPC+VIM \\
KP15 & + & KPC/MBL & KPC & KPC+VIM \\
KP16 & + & KPC & KPC & KPC \\
KP17 & + & KPC/MBL & VIM & VIM \\
KP18 & + & KPC & KPC & KPC \\
KP19 & - & KPC/MBL & KPC+VIM & KPC+VIM \\
\hline
\end{tabular}

MHT: Modified Hodge test, CDT: combined disk test, IT: immunochromatographic test. 


\section{Discussion}

AMR is becoming the most significant public health problem of the 21st century and is linked to factors related to the overuse or misuse of antimicrobials in human and veterinary practice, and to environmental pollution. Addressing the AMR phenomenon effectively requires close collaboration under a "one health" approach, taking into account the interconnections between human health, animal health and the environment. Most often, AMR occurs in healthcare settings due to non-prudent use of antimicrobials and the lack of effective infection control policy. The role of the aquatic environment as a route of pathogens transmission has long been recognized and it is commonly associated with effluents of wastewaters from hospitals, animal breeding farms and urban sewage infrastructures. Yet, there is no robust evidence on the circumstances or pathways initiating the emergence and transmission of drug-resistant strains to humans [31,32]. Recent studies show that not only bacteria but also bacterial genes can move freely among humans, animals and the environment [33-35]. Hence the risk of AMR transmission from the environment to humans has to be assessed based on both the resistant bacteria and the resistance genes circulating in the environment. In our study we examined both resistant bacteria and specific resistance genes focusing on clinically important strains in order to contribute more data in this field.

There are limited published data relating to the dissemination of clinically important MRSA, VRSA and VRE isolates and resistance genes from hospital and urban wastewater treatment plants and other sources such as farm animals and foods of animal origin [36-41]. The issue of resistant staphylococci and enterococci is of outmost importance, because both microorganisms have emerged as predominant pathogens in hospital infections during the last two decades. In the present study, the rate of MRSA strains demonstrating resistance against fluoroquinolones and macrolides was very high (100\%), while the prevalence of VRSA strains was rather low (16.7\%). Mandal et al. [38] reported 90\% MRSA and 15\% VRSA from hospital effluents in West Bengal, while Gomez et al. [40] reported only one isolation of MRSA strain from urban wastewater treatment plants in La Rioja, Spain. Two studies at Thibodaux (Louisiana, USA) showed persistent presence of MRSA and resistance genes in both raw and treated sewage $[39,41]$. Little information is available in relation to the prevalence of VRE strains in non-hospital environments. A publication relating to VRE and VanA genes in the aquatic environment has been reported in Pinellas County (Florida, USA) after an accidental release of untreated sewage [42]. In another study, VRE with similar multidrug-resistant patterns were isolated from patients, hospital effluents and urban wastewater, providing strong evidence of spreading such resistant bacteria from hospital sewage to the environment [43].

In our study the resistant Gram-negative rods (GNR) were a common finding, confirming their increased prevalence in hospital-associated drug-resistant infections. The reported rise of ESBL and carbapenemase-producing Enterobacteriaceae and non-fermenting GNR, mainly E. coli, K. pneumoniae, Enterobacter spp, A. baumannii and P. aeruginosa in hospital wastewater treatment plants is a matter of particular health concern but it has gained research attention only recently [7,44-49]. There are few studies assessing the presence of resistant GNR and resistant genes in hospital wastewaters while data on their occurrence in untreated hospital wastewaters are scarcer. Taking into account that during the last fifteen years the aforementioned GNR have become of major health concern as principal agents of drug-resistant infections, any evidence on their presence in untreated hospital wastewater is important. In our study, the commonest resistant isolates correspond to E. coli and K. pneumoniae. In particular for K. pneumoniae, we found that most isolates $(79.2 \%)$ encoded class A ( $\left.b l a_{\mathrm{KPC}}\right)$ carbapenemase-which is currently the most prevalent-and class B (bla $a_{\mathrm{NDM}}$ and $\left.b l a_{\mathrm{VIM}}\right)$ enzymes, while co-production of both KPC and MBL genes (Table 2), was demonstrated in eight strains (42.1\%); this observation coincides with the findings reported for clinical isolates by other researchers in Greece [22,50].

Interestingly, the majority $(77.8 \%)$ of the multiresistant $P$. aeruginosa strains were susceptible to colistin (Table 1), a polymyxin which has been used extensively in the past (1940s-1970s) against Gram-negative bacteria but was abandoned because of its nephrotoxic and neurotoxic side-effects. However, this forgotten drug got back in use in the early 2000s due to the emergence of 
carbapenem-resistant Gram-negative bacteria which were found to be susceptible to polymyxins [51]. Unfortunately, as the use of colistin increased, the colistin resistance among carbapenem-resistant GNR increased as well [52]. Two recent multicenter clinical and laboratory studies on carbapenem-resistant K. pneumoniae isolates from medical centers in U.S.A revealed colistin-resistance in $13 \%$ and $16 \%$ of the isolates $[53,54]$. In the present study colistin-resistance was observed in $22.2 \%$ of the P. aeruginosa isolates (Table 1) indicating colistin-resistance development in this country too. Yet, since the prospect of novel alternative antimicrobials for treatment of multidrug-resistant infections in the near future is uncertain, colistin can act as an effective antipseudomonal agent. In our study one carbapenem-resistant $K$. pneumoniae isolate was found resistant to tigecycline (5.3\%), a glycylcycline antibiotic which is currently used as a last-line treatment in severe infections caused by multidrug-resistant Gram-positive and Gram-negative pathogens. In two previous studies tigecycline was the most appropriate therapeutic approach against infections caused by carbapenem-resistant K. pneumoniae, among intensive care unit and tertiary care center patients $[55,56]$. It has been reported that the combination treatment scheme of both colistin and tigecycline may act synergistically against carbapenemem-resistant infections providing low rates of mortality [57].

Tracking the transportation of carbapenemase resistance genes among hospital settings, treated and untreated wastewaters, and the environment is important for planning effective surveillance, prevention and infection control strategies but requires methods easily applied in routine labs. An accurate and cost-effective assessment of carbapenemases' production is of urgent need, particularly in high-endemic regions. In our study we used a new rapid immunochromatographic assay and two standard phenotyping methods (MHT, CDT) to determine the type of produced carbapenemases. Results obtained by the aforementioned techniques were compared to those from a multiplex PCR assay which is recognized as the "gold standard" method. The employed phenotypic methods are considered useful, rapid, and cost-effective for the detection of carbapenemases; however, according to our results (Table 2), although rapid and inexpensive, they do not provide specific information about the type of carbapenemases. CDT detects KPC and MBL carbapenemases and thus is more sensitive than MHT which detects carbapenemases without differentiating them. In previous studies CDT exhibited sensitivity of $94.8 \%(87.8 \%-98 \%)$ and specificity of $100 \%(95-100 \%)$ for detecting carbapenemase-producing Enterobacteriaceae [21], while MHT's sensitivity and specificity were $92.7 \%$ and $63.4 \%$ respectively [58]. The IT rapid assay performed remarkably well producing reliable results, almost identical with those produced by the PCR. The two methods produced different results for only two out of the $19 \mathrm{~K}$. pneumoniae strains examined, with IT detecting one carbapenemase gene instead of two detected by PCR (Table 2, Figure 1). According to our results, and taking into consideration that rapid assays are extensively used in point-of-care testing, saving time and producing quite reliable results, they can be used for specimen other than clinical. The IT used in the present study performed very sufficiently and could be used for the fast detection and characterization of the four most commonly produced K. pneumoniae carbapenemases in wastewater samples, especially when PCR is not available in the laboratory.

\section{Conclusions}

In conclusion, our results demonstrated the presence of important clinical pathogens in raw hospital sewage, which are likely to be released in the environment. Hospital wastewaters are considered "hot spots" of antibiotic resistant bacteria, resistance genes, and mobile genetic elements no matter whether they are treated or not, since there are different sewage treatment technologies which may have diverse effects on microbial communities; in this respect there is a knowledge gap regarding the fate of resistant bacteria and genetic elements during wastewater treatment processes. Still there remain several further knowledge gaps that have to be filled in order to control and mitigate efficiently the emergence and spread of AMR in the environment. AMR is developing through complex interactions including de-novo mutation under clinical antibiotic pressure, the acquisition of mobile genes that evolve progressively in environmental bacteria, rapid demographic changes, human and 
animal population movement, as well as agricultural, landscape, climate and environmental changes. Giving more attention to how anthropogenic activities are influencing the evolution of antimicrobial resistance and broad, multisectoral and interdisciplinary collaboration are key-factors in addressing the rise of AMR.

Supplementary Materials: The following are available online at http://www.mdpi.com/2079-6382/8/3/85/s1, Table S1: Antibiotic resistance profile of Staphylococcus aureus, Table S2: Antibiotic resistance profile of Enterococcus spp., Table S3: Antibiotic resistance profile of Escherichia coli. Table S4: Antibiotic resistance profile of Klebsiella pneumoniae. Table S5: Antibiotic resistance profile of Pseudomonas aeruginosa.

Author Contributions: H.S.; Conceptualization, Methodology, Investigation, Visualization, Writing-Original Draft Preparation, Writing-Review \& Editing, P.B.; Methodology, Investigation, Visualization, Writing-Original Draft Preparation, Writing-Review \& Editing, A.I.; Methodology, Investigation, Data Curation, Formal Analysis, G.M.; Methodology, Investigation, Data Curation, Formal Analysis, C.P.; Visualization, Validation, Writing-Review \& Editing, Supervision.

Funding: This research received no external funding.

Conflicts of Interest: The authors declare no conflicts of interest with any companies or organizations whose products or services may be discussed in this article.

\section{References}

1. Aminov, R.I. A brief history of the antibiotic era: Lessons learned and challenges for the future. Front. Microbiol. 2010, 134, 1-7. [CrossRef]

2. Sabri, N.A.; Schmitt, H.; Van der Zaan, B.; Gerritsen, H.W.; Zuidema, T.; Rijnaarts, H.H.M.; Langenhoff, A.A.M. Prevalence of antibiotics and antibiotic resistance genes in a wastewater effluent-receiving river in the Netherlands. J. Environ. Chem. Eng. 2018, (in press). [CrossRef]

3. Bhagirath, A.; Yangi, L.; Patidar, R.; Yerex, K.; Ma, X.; Kumar, A.; Duan, K. Two Component Regulatory Systems and Antibiotic Resistance in Gram-Negative Pathogens. Int. J. Mol. Sci. 2019, 20, 1781. [CrossRef]

4. Parvez, S.; Khan, A. Hospital sewage water: A reservoir for variants of New Delhi metallo- $\beta$-lactamase (NDM)- and extended-spectrum $\beta$-lactamase (ESBL)-producing Enterobacteriaceae. Int. J. Antimicrob. Agents 2018, 51, 82-88. [CrossRef]

5. Kamaruzzaman, N.F.; Tan, L.P.; Hamdan, R.H.; Choong, S.S.; Wong, W.K.; Gibson, A.J.; Chivu, A.; Pina, M.F. Antimicrobial Polymers: The Potential Replacement of Existing Antibiotics? Int. J. Mol. Sci. 2019, $20,2747$. [CrossRef]

6. Galvin, S.; Boyle, F.; Hickey, P.; Vellinga, A.; Morris, D.; Cormican, M. Enumeration and characterization of antimicrobial-resistant Escherichia coli bacteria in effluent from municipal, hospital, and secondary treatment facility sources. Appl. Environ. Microbiol. 2010, 76, 4772-4779. [CrossRef]

7. Picão, R.C.; Cardoso, J.P.; Campana, E.H.; Nicoletti, A.G.; Petrolini, F.V.B.; Assis, D.M.; Juliano, L.; Gales, A.C. The route of antimicrobial resistance from the hospital effluent to the environment: Focus on the occurrence of KPC-producing Aeromonas spp. and Enterobacteriaceae in sewage. Diagn. Microbiol. Infect. Dis. 2013, 76, 80-85. [CrossRef]

8. Economou, V.; Sakkas, H.; Delis, G.; Gousia, P. Antibiotic resistance in Enterococcus spp. Friend or Foe? In Foodborne Pathogens and Antibiotic Resistance, 1st ed.; Singh, Om V., Ed.; Weinheim, Wiley-VCH Verlag GmbH \& Co.: Hoboken, NJ, USA, 2017; pp. 365-395.

9. Sidler, J.; Battegay, M.; Tschudin-Sutter, S.; Widmer, A.; Weisser, M. Enterococci, Clostridium difficile, and ESBL-producing bacteria: Epidemiology, clinical impact and prevention in ICU patients. Swiss Med. Wkly. 2014, 144, w14009. [CrossRef]

10. Falcone, M.; Russo, A.; Venditti, M. Optimizing antibiotic therapy of bacteremia and endocarditis due to staphylococci and enterococci: New insights and evidence from the literature. J. Infect. Chemother. 2015, 21, 330-339. [CrossRef]

11. European Centre for Disease Prevention and Control. Surveillance of antimicrobial resistance in Europe. Annual report of the European Antimicrobial Resistance Surveillance Network (EARS-Net) 2017. Stockholm: ECDC. 2018. Available online: https://ecdc.europa.eu/sites/portal/files/documents/EARS-Net-report-2017update-jan-2019.pdf (accessed on 5 June 2019). 
12. Howard, A.; O'Donoghue, M.; Feeney, A.; Sleator, R.D. Acinetobacter baumannii: An emerging opportunistic pathogen. Virulence 2012, 3, 243-250. [CrossRef]

13. Esposito, S.; De Simone, G. Update on the main MDR pathogens: Prevalence and treatment options. Infez. Med. 2017, 25, 301-310. [PubMed]

14. Daoud, Z.; Farah, J.; Sokhn, E.S.; El Kfoury, K.; Dahdouh, E.; Masri, K.; Afif, C.; Abdel-Massih, R.M.; Matar, G.M. Multidrug-Resistant Enterobacteriaceae in Lebanese Hospital Wastewater: Implication in the One Health Concept. Microb. Drug Resist. 2018, 24, 166-174. [CrossRef] [PubMed]

15. Holt, K.E.; Wertheim, H.; Zadoks, R.N.; Baker, S.; Whitehouse, C.A.; Dance, D.; Jenney, A.; Connor, T.R.; Hsu, L.Y.; Severin, J.; et al. Genomic analysis of diversity, population structure, virulence, and antimicrobial resistance in Klebsiella pneumoniae, an urgent threat to public health. Proc. Natl. Acad. Sci. USA 2015, 112, E3574-81. [CrossRef] [PubMed]

16. Hou, X.H.; Song, X.Y.; Ma, X.B.; Zhang, S.Y.; Zhang, J.Q. Molecular characterization of multidrug-resistant Klebsiella pneumoniae isolates. Braz. J. Microbiol. 2015, 46, 759-768. [CrossRef] [PubMed]

17. Runcharoen, C.; Moradigaravand, D.; Blane, B.; Paksanont, S.; Thammachote, J.; Anun, S.; Parkhill, J.; Chantratita, N.; Peacock, S. Whole genome sequencing reveals high-resolution epidemiological links between clinical and environmental Klebsiella pneumoniae. Genome Med. 2017, 9, 6. [CrossRef] [PubMed]

18. European Centre for Disease Prevention and Control (2015) Annual epidemiological report 2014. Antimicrobial resistance and healthcare-associated infections. Available online: https:/ecdc.europa.eu/sites/portal/files/media/en/publications/Publications/antimicrobial-resistanceannual-epidemiological-report.pdf (accessed on 12 January 2019).

19. Findlay, J.; Hopkins, K.L.; Alvarez-Buylla, A.; Meunier, D.; Mustafa, N.; Hill, R.; Pike, R.; McCrae, L.X.; Hawkey, P.M.; Woodford, N. Characterization of carbapenemase-producing Enterobacteriaceae in the West Midlands region of England: 2007-14. J. Antimicrob. Chemother. 2017, 72, 1054-1062. [CrossRef]

20. Clinical and Laboratory Standards Institute (CLSI). Performance standards for antimicrobial susceptibility testing, 27th ed.; Clinical and Laboratory Standards Institute: Wayne, PA, USA, 2017.

21. Pournaras, S.; Zarkotou, O.; Poulou, A.; Kristo, I.; Vrioni, G.; Themeli-Digalaki, K.; Tsakris, A. A combined disk test for direct differentiation of carbamenemase-producing Enterobacteriaceae in surveillance rectal swabs. J. Clin. Microbiol. 2013, 51, 2986-2990. [CrossRef]

22. Tsakris, A.; Poulou, A.; Pournaras, S.; Voulgari, E.; Vrioni, G.; Themeli-Digalaki, K.; Petropoulou, D.; Sofianou, D. A simple phenotypic method for the differentiation of metallo-beta-lactamases and classA KPC carbapenemases in Enterobacteriaceae clinical isolates. J. Antimicrob. Chemother. 2010, 65, 1664-1671. [CrossRef]

23. Cointe, A.; Bonacorsi, S.; Truong, J.; Hobson, C.; Doit, C.; Monjault, A.; Bidet, P.; Birgy, A. Detection of carbapenemases-producing Enterobacteriaceae in positive blood culture using Immunochromatographic RESIST-4 O.K.N.V assay. Antimicrob. Agents Chemother. 2018. [CrossRef]

24. Greissl, C.; Saleh, A.; Hamprecht, A. Rapid detection of OXA-48-like, KPC, NDM, and VIM carbapenemases in Enterobacterales by a new multiplex immunochromatographic test. Eur. J. Clin. Microbiol. Infect. Dis. 2018. [CrossRef]

25. Kolenda, C.; Benoit, R.; Carricajo, A.; Bonnet, R.; Dauwalder, O.; Laurent, F. Evaluation of the New Multiplex Immunochromatographic O.K.N.V. K-SeT Assay for Rapid Detection of OXA-48-like, KPC, NDM, and VIM Carbapenemases. J. Clin. Microbiol. 2018, 56. [CrossRef]

26. Baeza, L.L.; Pfennigwerth, N.; Greissl, C.; Göttig, S.; Saleh, A.; Stelzer, Y.; Gatermann, S.G.; Hamprecht, A. Comparison of five methods for detection of carbapenemases in Enterobacterales with proposal of a new algorithm. Clin. Microbiol. Infect. 2019. [CrossRef] [PubMed]

27. Rösner, S.; Kamalanabhaiah, S.; Küsters, U.; Kolbert, M.; Pfennigwerth, N.; Mack, D. Evaluation of a novel immunochromatographic lateral flow assay for rapid detection of OXA-48, NDM, KPC and VIM carbapenemases in multidrug-resistant Enterobacteriaceae. J. Med. Microbiol. 2019, 68, 379-381. [CrossRef] [PubMed]

28. Glupczynski, Y.; Evrard, S.; Huang, T.D.; Bogaerts, P. Evaluation of the RESIST-4 K-SeT assay, a multiplex immunochromatographic assay for the rapid detection of OXA-48-like, KPC, VIM and NDM carbapenemases. J. Antimicrob. Chemother. 2019, 6. [CrossRef] [PubMed]

29. Poirel, L.; Walsh, T.; Cuvillier, V.; Nordmann, P. Multiplex PCR for detection of acquired carbapenemase genes. Diagn. Microbiol. Infect. Dis. 2011, 70, 119-123. [CrossRef] [PubMed] 
30. Depardieu, F.; Perichon, B.; Courvalin, P. Detection of the van Alphabet and identification of enterococci and staphylococci at the species level by multiplex PCR. J. Clin. Microbiol. 2004, 42, 5857-5860. [CrossRef]

31. Galler, H.; Feierl, G.; Petternel, C.; Reinthaler, F.; Haas, D.; Habib, J.; Kittinger, C.; Luxner, J.; Zarfel, G. Multiresistant bacteria isolated from activated sludge in Austria. Inter. J. Environ. Res. Public Health 2018, 15, 479. [CrossRef]

32. Quach-Cu, J.; Herrera-Lynch, B.; MarciniaK, C.; Adams, S.; Simmerman, A.; Reinke, R. The effect of primary, secondary, and tertiary wastewater treatment processes on antibiotic resistance gene (ARG) concentrations in solid and dissolved wastewater fractions. Water 2018, 10, 37. [CrossRef]

33. Manaia, C.M. Assessing the risk of antibiotic resistance transmission from the environment to humans: Non-direct proportionality between abundance and risk. Trends Microbioliol. 2017, 25, 173-181. [CrossRef]

34. Oliveira, P.H.; Touchon, M.; Cury, J.; Rocha, E.P.C. The chromosomal organization of horizontal gene transfer in bacteria. Nat. Commun. 2017, 8, 841. [CrossRef]

35. Martínez, J.L. Ecology and evolution of chromosomal gene transfer between environmental microorganisms and pathogens. Microbiol. Spectr. 2018, 6. [CrossRef]

36. Economou, V.; Gousia, P. Agriculture and food animals as a source of antimicrobial-resistant bacteria. Infect. Drug Resist. 2015, 8, 49-61. [CrossRef]

37. Gousia, P.; Economou, V.; Bozidis, P.; Papadopoulou, C. Vancomycin-Resistance Phenotypes, Vancomycin-Resistance Genes and Resistance to antibiotics of Enterococci isolated from Food of animal origin. Foodborne Pathog. Dis. 2015, 12, 214-220. [CrossRef] [PubMed]

38. Mandal, S.M.; Ghosh, A.K.; Pati, B.R. Dissemination of antibiotic resistance in methicillin-resistant Staphylococcus aureus and vancomycin-resistant $\mathrm{S}$ aureus strains isolated from hospital effluents. Am. J. Infect. Control 2015, 43, e87-e88. [CrossRef] [PubMed]

39. Naquin, A.; Shrestha, A.; Sherpa, M.; Nathaniel, R.; Boopathy, R. Presence of antibiotic resistance genes in a sewage treatment plant in Thibodaux, Louisiana, USA. Bioresour. Techol. 2015, 188, 79-83. [CrossRef] [PubMed]

40. Gómez, P.; Lozano, C.; Benito, D.; Estepa, V.; Tenorio, C.; Zarazaga, M.; Torres, C. Characterization of staphylococci in urban wastewater treatment plants in Spain, with detection of methicillin resistant Staphylococcus aureus ST398*. Environ. Pollut. 2016, 212, 71-76. [CrossRef]

41. Boopathy, R. Presence of Methicillin Resistant Staphylococcus aureus (MRSA) in sewage treatment plant. Bioresour. Techol. 2017, 240, 144-148. [CrossRef] [PubMed]

42. Young, S.; Nayak, B.; Sun, S.; Badgley, B.; Rohr, J.; Harwood, V. Vancomycin-resistant enterococci and bacterial community structure following a sewage spill into an aquatic environment. Appl. Environ. Microbiol. 2016, 82, 5653-5660. [CrossRef]

43. Varela, A.R.; Ferro, G.; Vredenburg, J.; Yanike, M.; Vieira, L.; Rizzo, L.; Lameiras, C.; Manaia, M. Vancomycin resistant enterococci: From the hospital effluent to the urban wastewater treatment plant. Sci. Total Environ. 2013, 450-451, 155-161. [CrossRef] [PubMed]

44. Korzeniewska, E.; Korzeniewska, A.; Harnisz, M. Antibiotic resistant Escherichia coli in hospital and municipal sewage and their emission to their environment. Exotoxicol. Environ. Safety 2013, 91, 96-102. [CrossRef] [PubMed]

45. Kalaiselvi, K.; Mangayarkarasi, V.; Balakrishnan, D.; Chitraleka, V. Survival of antibacterial resistance microbes in hospital-generated recycled wastewater. J. Water Health 2016, 14, 942-949. [CrossRef] [PubMed]

46. Lamba, M.; Graham, D.; Ahammad, S.Z. Hospital wastewater releases of carbapenem-resistance pathogens and genes in urban India. Environ. Sci. Technol. 2017, 51, 13906-13912. [CrossRef] [PubMed]

47. Rabbani, M.A.G.; Howlader, Z.H.; Kabir, Y. Detection of multidrug resistant (MDR) bacteria in untreated wastewater disposals of hospitals in Dhaka City, Bangladesh. J. Global Antimicrob. Resist. 2017, 10, 120-125. [CrossRef] [PubMed]

48. Haller, L.; Chen, H.; Ng, C.; Le, T.H.; Koh, T.H.; Barkham, T.; Sobsey, M.; Gin, K.Y. Occurrence and characteristics of extended-spectrum $\beta$-lactamase- and carbapenemase- producing bacteria from hospital effluents in Singapore. Sci. Total Environ. 2018, 615, 1119-1125. [CrossRef] [PubMed]

49. Wang, Q.; Wang, P.; Yang, Q. Occurrence and diversity of antibiotic resistance in untreated hospital wastewater. Sci. Total Environ. 2018, 621, 990-999. [CrossRef] [PubMed] 
50. Giakkoupi, P.; Pappa, O.; Polemis, M.; Vatopoulos, A.C.; Miriagou, V.; Zioga, A.; Papagiannitsis, C.C.; Tzouvelekis, L.S. Emerging Klebsiella pneumoniae isolates coproducing KPC-2 and VIM-1 carbapenemases. Antimicrob. Agents Chemother. 2009, 53, 4048-4050. [CrossRef] [PubMed]

51. Falagas, M.E.; Kasiakou, S.K. Colistin: The revival of polymyxins for the management of multidrug-resistant Gram-negative bacterial infections. Clin. Infect. Dis. 2005, 40, 1333-1341. [CrossRef] [PubMed]

52. Satlin, M.J. The Search for a Practical Method for Colistin Susceptibility Testing: Have We Found It by Going Back to the Future? J. Clin. Microbiol. 2019, 57, e01608-18. [CrossRef] [PubMed]

53. Rojas, L.J.; Salim, M.; Cober, E.; Richter, S.S.; Perez, F.; Salata, R.A.; Kalayjian, R.C.; Watkins, R.R.; Marshall, S.; Rudin, S.D.; et al. Antibacterial Resistance Leadership Group. Colistin resistance in carbapenem-resistant Klebsiella pneumoniae: Laboratory detection and impact on mortality. Clin. Infect. Dis. 2017, 64, 711-718. [PubMed]

54. Satlin, M.J.; Chen, L.; Patel, G.; Gomez-Simmonds, A.; Weston, G.; Kim, A.C.; Seo, S.K.; Rosenthal, M.E.; Sperber, S.J.; Jenkins, S.G.; et al. Multicenter clinical and molecular epidemiological analysis of bacteremia due to carbapenem-resistant Enterobacteriaceae (CRE) in the CRE epicenter of the United States. Antimicrob. Agents Chemother. 2017, 61, e02349-16. [CrossRef] [PubMed]

55. Li, Y.; Shen, H.; Zhu, C.; Yu, Y. Carbapenem-Resistant Klebsiella pneumoniae Infections among ICU Admission Patients in Central China: Prevalence and Prediction Model. Biomed. Res. Int 2019, 9767313. [CrossRef] [PubMed]

56. Saeed, N.K.; Alkhawaja, S.; Azam, N.F.; Alaradi, K.; Al Biltagi, M. Epidemiology of carbapenem-resistant Enterobacteriaceae in a Tertiary Care Center in the Kingdom of Bahrain. J. Lab. Physicians 2019, 11, 111-117. [CrossRef] [PubMed]

57. Aygun, F.; Aygun, F.D.; Varol, F.; Durak, C.; Çokuğraş, H.; Camcığlu, Y.; Cam, H. Infections with Carbapenem-Resistant Gram-Negative Bacteria are a Serious Problem Among Critically Ill Children: A Single-Centre Retrospective Study. Pathogens 2019, 8, 69. [CrossRef] [PubMed]

58. Mathers, A.; Carroll, J.; Sifri, C.; Hazen, K. Modified Hodge Test versus Indirect Carbapenemase Test: Prospective Evaluation of a Phenotypic Assay for Detection of Klebsiella pneumoniae Carbapenemase (KPC) in Enterobacteriaceae. J. Clin. Microbiol. 2013, 51, 1291-1293. [CrossRef] [PubMed] 